\section{First multi-year retrospective study on Vibrio parahaemolyticus and Vibrio vulnificus prevalence in Ruditapes philippinarum harvested in Sacca di Goro, Italy}

\author{
Patrizia Serratore, Fabio Ostanello, \\ Pier Luca Passalacqua, Emanuele Zavatta, \\ Giorgia Bignami, Andrea Serraino, \\ Federica Giacometti \\ Department of Veterinary Medical \\ Sciences, Alma Mater Studiorum- \\ University of Bologna, Ozzano dell'Emilia \\ (BO) Italy
}

\section{Abstract}

The present work describes a retrospective study aiming to verify a possible correlation between the environmental conditions (temperature, salinity and dissolved oxygen), the abundance of Vibrio spp., and the prevalence of $V$. parahaemolyticus and $V$. vulnificus in the Manila clam $R$. philippinarum harvested in Sacca di Goro, Emilia-Romagna Region, Northern Italy. On the whole, 104 samples, collected in the period 2007-2015 and submitted to microbiological analyses (isolation and genotyping), have been reconsidered for Vibrio spp. load, $V$. parahaemolyticus prevalence (total, gene marker toxRP; potentially pathogenic, gene markers $t d h$ and/or trh) and $V$. vulnificus prevalence (total, gene markers vvhA and $h s p$ ) together with environmental data obtained from the monitoring activity of the Emilia-Romagna Regional Agency for the Prevention, the Environment and the Energy. Environmental data have been processed to calculate the median of each, assessing the seasonal range of seawater temperature (warmer months: April-0ctober, $\mathrm{T}^{\circ} \mathrm{C}>16.45^{\circ} \mathrm{C}$; cooler months November-March, $\quad \mathrm{T}^{\circ} \mathrm{C}$ $<16.45^{\circ} \mathrm{C}$ ), salinity (<or $>27 \mathrm{psu}$ ), and dissolved oxygen (< or $>8.2 \mathrm{mg} / \mathrm{L})$. Total $V$. vulnificus, total and potentially pathogenic $V$. parahaemolyticus were present respectively in the $11.5,29.8$ and $6.7 \%$ of the samples. The Vibrio spp. load (mean value of $4.69 \pm 0.65 \log _{10}$ colony forming unit $\mathrm{g}^{-1}$ ) and the prevalence of potentially pathogenic $V$. parahaemolyticus, were not significantly correlated to the environmental conditions $(\mathrm{P}>0.05)$, whereas the prevalence of both total $V$. vulnificus and total $V$. parahaemolyticus was significantly higher in the warmer period $(\mathrm{P}<0.05)$, without correlation with salinity and dissolved oxygen values $(\mathrm{P}>0.05)$

\section{Introduction}

Vibrio parahaemolyticus and Vibrio vulnificus are ubiquitous Gram-negative bacterial pathogens found naturally in marine and estuarine waters, representing a leading cause of seafood-associated bacterial illness. The most important vehicle for these microorganisms are raw or lightly cooked bivalve shellfish (Drake et al., 2007), hereafter indicated simply shellfish. Although both $V$. vulnificus and $V$. parahaemolyticus cases occur sporadically, the former are almost always sporadic while the latter can also occur in outbreak settings (Drake et al., 2007).

V. parahaemolyticus infection commonly include abdominal cramps, diarrhea, nausea, headaches, fever and chills (Baker-Austin et al., 2010). Most environmental V. parahaemolyticus strains are considered to be nonpathogenic due to low detection frequencies of $t d h$ and $t r h$ genes encoding respectively for the thermostable direct haemolysin (TDH) and the TDH-related haemolysin (TRH), therefore these gene markers continues to be the simplest and most frequently used diagnostic indicator of pathogenicity (Gutierrez West et al., 2013; Raghunath, 2015).

$V$. vulnificus infection may be acquired via wound infections or consumption of raw seafood, particularly shellfish, and may result highly invasive, causing respectively secondary or primary septicemia, particularly in highrisk populations, including patients with chronic liver disease, immunodeficiency, iron storage disorders, end-stage renal disease, and diabetes mellitus (Horseman and Surani, 2011). The presence/absence of many gene target have been used to differentiate clinical from environmental $V$. vulnificus strains, and among them $v c g \mathrm{C}$ and $v c g \mathrm{E}$ (Han et al., 2011); 16S rRNA type A, B or $\mathrm{AB}$ and CPS operon group 1 allele 1 (CPS1) and allele 2 (CPS2), (Chatzidaki-Livanis et al., 2006). In any case, unique virulence gene markers that are present exclusively in virulent $V$. vulnificus strains have not yet been identified (Han et al., 2009), therefore according to FAO/WHO (2005), all $V$. vulnificus strains may be considered virulent.

The abundance and distribution of Vibrio parahaemolyticus and Vibrio vulnificus have been linked to environmental factors, most notably temperature, salinity and dissolved oxygen (Parveen et al., 2008; Ramirez et al., 2009), even if predictive relationships may vary across Regions due to differences in ecology. Currently there is scant information on both the spatial distribution and seasonal detection of Vibrio spp. in shellfish harvested in the Emilia-Romagna Region, and other Italian production areas as well, giving that only a few data are available, mostly from lim-
Correspondence: Patrizia Serratore, Department of Veterinary Medical Science, Special Operative Unit of Aquaculture and Hygiene of Fishery Products, v.le A. Vespucci 2, 47042 Cesenatico (FC), Italy.

Tel: +39.0547 .338948 - Fax: +39.0547 .338941 .

E-mail: patrizia.serratore@unibo.it

Key words: Vibrio parahaemolyticus; Vibrio vulnificus; Ruditapes philippinarum; Environmental conditions; Italy.

Contributions: the multi-year survey (2007-2015) on the prevalence of $V$. parahaemolyticus and $V$. vulnificus in $R$. philippinarum, was realized by PS, EZ, GB, PLP. Environmental data processing and statistical analyses were performed by F0, FG and AS.

Conflict of interest: the authors declare no potential conflict of interest.

Funding: this work was realized utilizing data from previous research activities, without costs from the Department of Veterinary Medical Sciences, Alma Mater Studiorum-University of Bologna, Bologna, Italy.

Acknowledgments: authors wish to thank Dr. Cristina Mazziotti of the Regional Agency for the Prevention, the Environment and the Energy (Arpae) of Emilia-Romagna, who provided the environmental data of interest from the annual reports of the oceanographic vessel Daphne II.

Received for publication: 15 July 2016.

Accepted for publication: 21 September 2016.

This work is licensed under a Creative Commons Attribution-NonCommercial 4.0 International License (CC BY-NC 4.0)

(C) Copyright P. Serratore et al., 2016

Licensee PAGEPress, Italy

Italian Journal of Food Safety 2016; 5:6161

doi:10.4081/ijfs.2016.6161

ited research activities. Clearly, human exposure to these pathogens cannot be completely eliminated, but the incidence of illness can be reduced if environmental conditions that significantly elevate risk can be identified and monitored (Johnson et al., 2012). To our knowledge, this study represent the first attempt to determine the relationships between environmental conditions (seawater temperature, salinity and dissolved oxygen) and Vibrio population in the Manila clam Ruditapes philippinarum, hereafter indicated simply clam, utilizing a multi years (20072015) retrospective study, where Vibrio spp. abundance, the total $V$. parahaemolyticus (tox $\mathrm{RP}+)$, the potentially pathogenic $V$. parahaemolyticus (tdh+ and or trh+), and the total V. vulnificus (vvhA+ and $h s p+$ ) have been considered. 


\section{Materials and Methods}

\section{Study area}

All clam samples were collected at the Sacca di Goro, Emilia-Romagna Region, Northern Italy (Figure 1), a wide sandy-bottomed lagoon of the Po river delta characterized by particular features suitable for the shellfish productions, particularly the Manila clam Ruditapes philippinarum and the mussel Mytilus galloprovincialis. The lagoon extends over 2000 hectares of shallow water, $60-70 \mathrm{~cm}$ on average, with a maximum depth of $200 \mathrm{~cm}$.

\section{Microbiological analyses}

On the whole, 104 samples of $R$. philippinarum, were collected in the study area, approximately on monthly basis, excluding August, in the period 2007-2015. The analytical protocols utilized at that time to ascertain the Vibrio spp. load, the prevalence of total (tox $\mathrm{RP}+$ ) and potentially pathogenic $V$. parahaemolyticus (tdh+ and or trh+), and the prevalence of total $V$. vulnificus (vvhA+ and $h s p+$ ) have been reported elsewhere (Passalacqua et al., 2016), including a more detailed genotyping approach for $V$. vulnificus isolates, characterized beyond the species level by means of other gene markers: $v c g C$, $v c g \mathrm{E}, 16 \mathrm{~S}$ rRNA type $\mathrm{A} / \mathrm{B} / \mathrm{AB}, \mathrm{CPS}$ operon group 1 allele 1 (CPS1) and allele 2 (CPS2).

\section{Environmental parameters}

Data of interest on seawater temperature, salinity and dissolved oxygen, were made available by the oceanographic vessel Daphne II (annual reports) of the Regional Agency for the Prevention, the Environment and the Energy - Emilia-Romagna (ARPAE).

\section{Statistical analyses}

Preliminarily, environmental parameters (seawater temperature, salinity and dissolved oxygen), collected monthly, were arbitrarily divided into two categories based on the median (warmer months: April-October, $\mathrm{T}^{\circ} \mathrm{C}>16.45^{\circ} \mathrm{C}$; cooler months NovemberMarch, $\mathrm{T}^{\circ} \mathrm{C}<16.45^{\circ} \mathrm{C}$ ); salinity ( $<$ or $>27 \mathrm{psu}$ ), and dissolved oxygen $(<$ or $>8.2 \mathrm{mg} / \mathrm{L})$. The Vibrio spp. load was log-transformed prior to the analysis. The Kolmogorov-Smirnov test for goodness of adaptation was used to verify distribution normality. On the basis of the results of this test, Student's t-test was used to compare the $\log _{10}$ Vibrio spp. load. Qualitative data [prevalence of $V$. parahaemolyticus (total, gene marker toxRP; potentially pathogenic, gene markers $t d h$ and/or trh) and $V$. vulnificus (total, gene markers $v v h$ A and $h s p$ )] were analyzed using chi-square test. All statistical analyses were performed using the software SPSS 23 (SPSS Inc., Chicago, IL, USA).

\section{Results}

In order to be concise, detail on the microbiological results of each of the 104 samples of clams are omitted. The Vibrio spp. load of each sample, expressed as Colony Forming Units $(\mathrm{CFU} \mathrm{g})^{-1}$ ) have been log-transformed prior to calculate the mean value, resulting $4.69 \pm 0.65$ $\log _{10} \mathrm{CFU} \mathrm{g} \mathrm{g}^{-1}$. With respect to the specific bacterial targets, on the whole $11.5 \%$ samples were positive for total $V$. vulnificus (vvhA+ and $h s p+), 29.8 \%$ were positive for total $V$. parahaemolyticus (tox $\mathrm{RP}+$ ), and $6.7 \%$ were positive for potentially pathogenic $V$. parahaemolyticus (tdh+ or trh+), none of the strains showing the double positivity). A total of 8 out of 43 positive samples showed the concurrent presence of $V$. parahaemolyticus and $V$. vulnificus, and, overall, 50 strains, respectively $16 \mathrm{~V}$. vulnificus and $34 \mathrm{~V}$. parahaemolyticus, were isolated. The isolation of strains with different virulence genes profiles in three samples for $V$. parahaemolyticus and in three sam- ples for $V$. vulnificus should be noted; details on the number of isolates of both $V$. parahaemolyticus and $V$. vulnificus with different virulence genes profiles in positive samples are reported in Table 1.

The environmental parameters considered in the present study are those collected from 2007 to 2013 , being data from 2014 to 2015 unavailable, through 68 sampling campaigns, by the oceanographic vessel Daphne II (ARPAE). Most of the samples were collected from January to December, and none of them was collected in August; one year (2007) showed a noticeable lower number of samples. Summary data of seawater temperature, salinity and dissolved oxygen are reported in Table 2. Considering the different years and the different months of clam sampling from 2007 to 2015 , the statistical analyses showed a mean prevalence of $29.81 \%$ for $V$. parahaemolyticus (total) and $11.5 \%$ of samples positive $V$. vulnificus (total), with a range respectively of 0.0 50 and $0.0-27.3 \%$ in different years, and with a range respectively of $0.0-100$ and $0.0-66.6 \%$ in different months. More details are reported in Table 3 . The majority of $V$. vulnificus strains (13 out of 16) were isolated during summer (June and July) whereas the majority of $V$. parahaemolyticus strains (28 out of 34 ) were isolated in a longer period, from June to October. The statistical analysis of the whole dataset $(n=104)$ showed a significant differences $(\mathrm{P}=0.00$ and $\mathrm{P}<0.01)$ of the prevalence of samples positive for $V$. parahaemolyticus (total) and $V$. vulnificus (total) between the warmer months period and the cooler months period (respectively 49.1 vs $6.3 \%$ and $21.4 \mathrm{vs}$ $0 \%)$. The same association was not shown (P>0.05) for potentially pathogenic V. parahaemolyticus (8.8 vs 4.2\%) and for Vibrio spp. load $\left(4.71 \pm 0.10\right.$ vs $\left.4.70 \pm 0.29 \log _{10} \mathrm{~g}^{-1}\right)$.

No significant relationships $(\mathrm{P}>0.05)$ were found between the prevalence of $V$. parahaemolyticus (total and potentially pathogen-

Table 1. Virulence genes profiles of Vibrio parahaemolyticus and Vibrio vulnificus isolates detected in 43 out of 104 samples of clams.

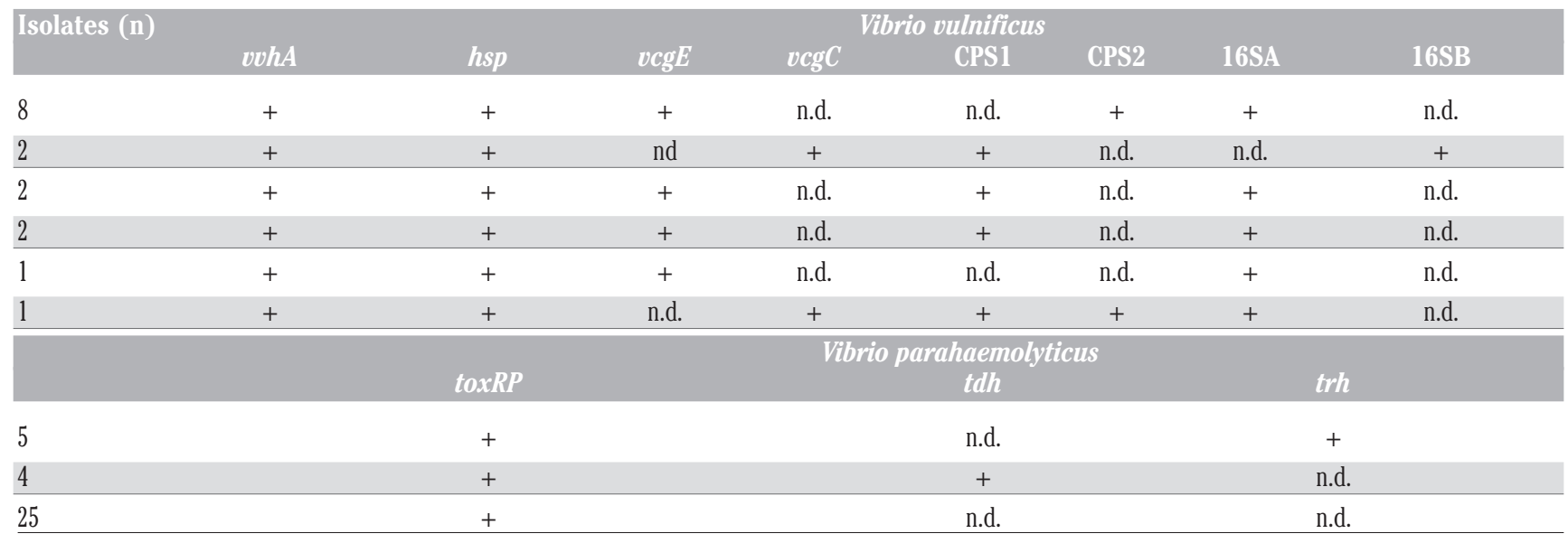

n.d., not detected. 
ic), V. vulnificus (total) and Vibrio spp. load and the others environmental parameters, namely seawater salinity and dissolved oxygen.

\section{Discussion}

In the present study, a sizeable number of samples (104) of $R$. philippinarum harvested in the same area has been considered over a very long period (from 2007 to 2015), therefore our results may be considered robust and suitable for a comparison with other extensive studies carried out in the Mediterranean area Among the few reports, this is the case of the multiyear study performed on different shellfish, including $R$. philippinarum (120 samples) harvested in the Ebro Delta, Spain, from 2006 to 2010 (Lopez-Joven et al., 2014, 2015), but our results are not in agreement, because we found an higher prevalence of total $\mathrm{V}$. parahaemolyticus (29.8 vs $14.2 \%$ ) and potentially pathogenic $V$. parahaemolyticus (6.7 vs 3.3\%), but a lower prevalence of total $V$. vulnificus (11.5 vs 22.5\%).

It is largely recognized that in coastal environments, as well as estuaries and coastal rivers, elevated water temperatures and low salinity levels are considered promoting factors for vibrios abundance (Hsieh et al., 2008; Oberbeckmann et al., 2012; Froelich et al., 2013; Takemura et al., 2014; Urquhart et al., 2016). According with these findings, in the present study the prevalence of total $V$. parahaemolyticus and total $V$. vulnificus resulted significantly higher in the warmer months (seawater temperature $>16.45^{\circ} \mathrm{C}, \mathrm{P}<0.05$ ), but not at the lower values of salinity $(<27 \mathrm{psu}$, $P>0.05)$, according to other studies, where salinity values resulted only marginally associ- ated (Parveen et al., 2008) or unrelated (Deepanjali et al., 2005) with the abundance of V. parahaemolyticus.

The correlation with salinity and V. vulnificus abundance is still unclear, giving that notwithstanding medium or low salinity (between 5 and $25 \mathrm{ppt}$ ) are largely considered the optimal environmental conditions (Mahmud et al., 2008), V. vulnificus has been isolated from waters with salinities ranging from 1 to 34 ppt (Parvathi et al., 2004).

Unlike the total $V$. parahaemolyticus, in our study the prevalence of the subpopulation of potentially pathogenic $V$. parahaemolyticus, characterized by the presence of $t d h$ and/or trh, resulted unrelated to seawater temperature, but it is important to outline that recently, a large number of clinical isolates revealed an unexplained number of strains lacking these genes, suggesting that $V$. parahaemolyticus may harbor other virulence factors (Ottaviani et al., 2012). Moreover it has been demonstrated that environmental isolates of $V$. parahaemolyticus lacking $t d h$ and/or trh are also highly cytotoxic to human gastrointestinal cells (Raghunath, 2015).

Researches on this topic are ongoing, and therefore to ascertain the pathogenic potential of environmental strains, and the potential risk for consumers, more gene markers other

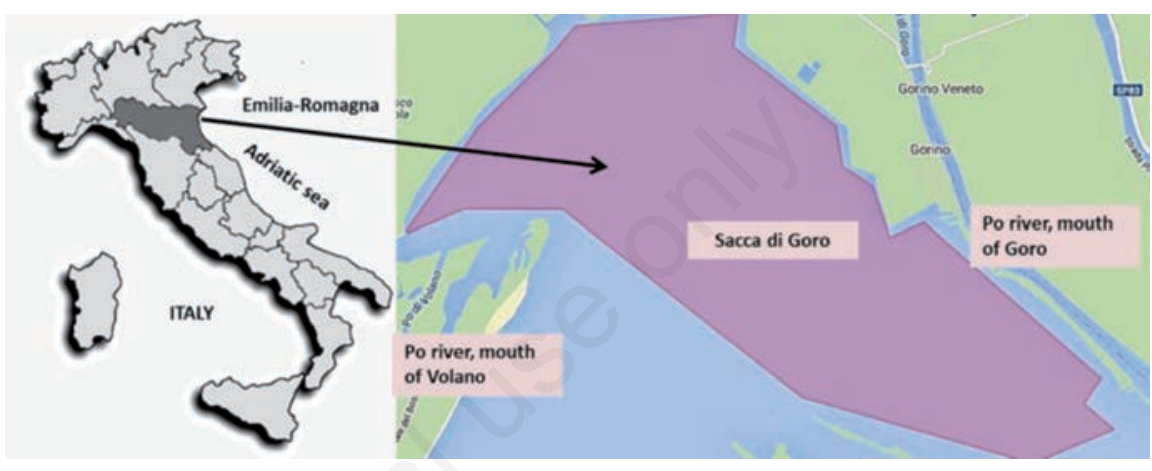

Figure 1. Sacca di Goro, Emilia-Romagna Region, Northern Italy.

Table 2. Summary data of seawater temperature, salinity and dissolved oxygen from 2007 to 2013.

\begin{tabular}{lccc} 
& Temperature $\left({ }^{\circ} \mathrm{C}\right)$ & Salinity (psu) & Dissolved $0 x y g$ gen $(\mathrm{mg} / \mathrm{L})$ \\
Mean & 16.94 & 26.12 & 8.79 \\
Median & 16.45 & 27.07 & 8.24 \\
\hline Minimum & 5.3 & 10.74 & 5.23 \\
Maximun & 28.73 & 37.62 & 14.49
\end{tabular}

Table 3. Number of clam samples analyzed per month from 2007 to 2015, Vibrio spp. load, number and percentage of samples positive for Vibrio vulnificus (total), Vibrio parahaemolyticus (total), and potentially pathogenic Vibrio parabaemolyticus.

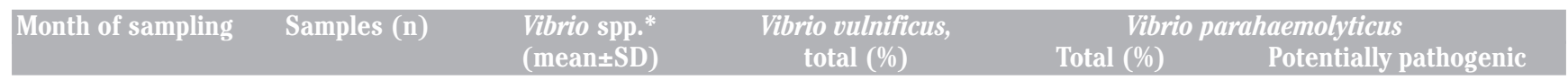

\begin{tabular}{|c|c|c|c|c|c|}
\hline \multicolumn{6}{|c|}{ Warmer months } \\
\hline April & 7 & $4.87 \pm 0.25$ & $1(14.3)$ & 0 & 0 \\
\hline May & 6 & $4.75 \pm 0.85$ & 0 & $1(14.3)$ & $1(16.7)$ \\
\hline June & 10 & $4.60 \pm 0.68$ & $5(50)$ & $10(100)$ & $2(20)$ \\
\hline July & 6 & $4.70 \pm 0.47$ & $4(66.6)$ & $3(50)$ & $1(16.7)$ \\
\hline September & 15 & $4.74 \pm 0.63$ & $1(6.7)$ & $7(46.7)$ & 0 \\
\hline October & 12 & $4.61 \pm 0.74$ & $1(8.3)$ & $7(53.8)$ & $1(7.69)$ \\
\hline \multicolumn{6}{|l|}{ Cooler months } \\
\hline January & 6 & $4.61 \pm 0.47$ & 0 & 0 & 0 \\
\hline February & 10 & $4.98 \pm 0.66$ & 0 & 0 & 0 \\
\hline March & 9 & $5.04 \pm 0.58$ & 0 & 0 & 0 \\
\hline November & 16 & $4.46 \pm 0.71$ & 0 & $3(17.6)$ & $2(12.5)$ \\
\hline December & 7 & $4.41 \pm 0.83$ & 0 & 0 & 0 \\
\hline Total warmer months & 56 & $4.71 \pm 0.10$ & $12(21.4)$ & $28(49.1)$ & $5(8.8)$ \\
\hline Total cooler months & 48 & $4.70 \pm 0.29$ & 0 & $3(6.3)$ & $2(4.2)$ \\
\hline
\end{tabular}


than $t d h$ and/or trh could be investigated.

With respect to dissolved oxygen, it has been reported a negative correlation with Vibrio spp. abundance (Siboni et al., 2016), and $V$. vulnificus abundance (Pfeffer et al., 2003), and a positive correlation with $V$. parahaemolyticus abundance (Parveen et al., 2008). This, notwithstanding, during our study dissolved oxygen varied from a minimum of 5.23 to a maximum of $14.49 \mathrm{mg} / \mathrm{L}$, neither Vibrio spp. load nor $V$. vulnificus (total) and $V$. parahaemolyticus (total and potentially pathogenic) prevalence resulted significantly related to this parameter.

\section{Conclusions}

Outbreaks of shellfish-associated infection have been reported worldwide, and among them Vibrio species lead the list of bacterial pathogens, therefore an understanding of the spatiotemporal dynamics of Vibrio population and its potential to cause disease outbreaks has become increasingly important (Oberbeckmann et al., 2012; Takemura et al., 2014). Moreover, this group of organisms is increasing in abundance as a consequence of environmental perturbations and climate change (Siboni et al., 2016). According to the European Environmental Agency, the rise of global sea surface temperature is one of the major physical impacts of climate change, and in coastal European seas it has increased 4-7 times faster over the past few decades than in the global oceans (Reid et al., 2011). This local increase in sea surface temperature has been linked to outbreaks of Vibrio-associated human illness caused by $V$. cholerae non-01 and non-0139, V. parahaemolyticus, and V. vulnificus in several European countries. However, the lack of mandatory notification systems for Vibrio-associated illnesses prevents accurate estimates of the number of Vibrio-infections occurring in Europe (Le Roux et al., 2015). It is clear that for an appropriate risk assessment on Vibrio-infections in Europe, robust data on the prevalence of the potentially pathogenic species in seawater and seafood, particularly shellfish, are essential, and the knowledge of the impact of the environmental conditions allowing to their proliferation is of paramount importance to define predictive models.

The assessment of the environmental state of European surface waters comprises the collection and aggregation of a huge amount of information, to provide, among others, a basis for the identification and assessment of environmental threats at Regional and global levels (EEA, 2015). Unfortunately the monitoring of vibrios in the coastal areas is not considered among the EEA indicators, and for the control of the shellfish production areas (Regulation EC 854/2004; European Commission, 2004a) as well, consequently, only few data provided by field researches are currently available.

In this respect, our retrospective multi-year study, the first one realized in Italy, suggests that the prevalence of total $V$. parahaemolyticus and total $V$. vulnificus in clams is positively correlated to the seawater temperature, and their prevalence may be considered threatening to human health, also because the purge of these microorganism, through the purification process applied according to the European legislation in force (Regulation EC 853/2004; European Commission, 2004b), may be considered substantially ineffective (Serratore et al., 2014).

\section{References}

Baker-Austin C, Stockley L, Rangdale, R, Martinez-Urtaza J, 2010. Environmental occurrence and clinical impact of Vibrio vulnificus and Vibrio parahaemolyticus: a European perspective. Environ Micro Rep 2:7-18.

Chatzidaki-Livanis M, Hubbard MA, Gordon K, Harwood WJ, Wright AC, 2006. Genetic distinctions among clinical and environmental strains of Vibrio vulnificus. Appl Environ Microb 72:6136-41.

Deepanjali A, Kumar HS, Karunasagar I, Karunasagar I, 2005. Seasonal variation in abundance of total and pathogenic Vibrio parahaemolyticus bacteria in oysters along the southwest coast of India. Appl Environ Microb 71:3575-80.

Drake SL, DePaola A, Jaykus LA, 2007. An overview of Vibrio vulnificus and Vibrio parahaemolyticus. Compr Rev Food Sci Food Saf 6:120-44.

EEA, 2015. Water. Status and monitoring overview. European Environment Agency. Available from: http://www.eea.europa.eu/themes/water/st atus-and-monitoring/intro-2013-overview

European Commission, 2004a. Regulation of the European Parliament and of the Council of 29 April 2004 laying down specific hygiene rules laying down specific hygiene rules for the hygiene of foodstuffs, 853/2004/CE. In: Official Journal, L 139/55, 30/04/2004.

European Commission, 2004b. Regulation of the European Parliament and of the Council of 29 April 2004 laying down specific rules for the organisation of official controls on products of animal origin intended for human consumption, 854/2004/CE. In: Official Journal, L 139/206, 30/04/2004.

FAO/WHO, 2005. Risk assessment of Vibrio vul- nificus in raw oysters. Interpretative summary and technical report. World Health Organization, Rome, Italy.

Froelich B, Bowen J, Gonzalez R, Snedeker A, Noble R, 2013. Mechanistic and statistical models of total Vibrio abundance in the Neuse River Estuary. Water Res 47:578393.

Gutierrez West C, Klein SL, Lovell CR, 2013. The virulence factor genes tdh, trh and th occur at high frequency in Vibrio parahaemolyticus isolated from a pristine estuary. Appl Environ Microb 79:2247-52.

Han F, Pu S, Hou A, Ge B, 2009. Characterization of clinical and environmental types of Vibrio vulnificus isolates from Louisiana oysters. Foodborne Pathog Dis 6:1251-8.

Han F, Wang F, Ge B, 2011. Detecting potentially virulent Vibrio vulnificus strains in raw oysters by quantitative loop-mediated isothermal amplification. Appl Environ Microb 77:2589-95.

Horseman MA, Surani S, 2011. A comprehensive review of Vibrio vulnificus: an important cause of severe sepsis and skin and soft-tissue infection. Appl Environ Microb 15:157-66.

Hsieh JL, Fries JS, Noble RT, 2008. Dynamics and predictive modelling of Vibrio spp. in the Neuse River Estuary, North Carolina, USA. Environ Microbiol 10:57-64.

Johnson CN, Bowers JC, Griffitt KJ, Molina V, Clostio RW, Pei S, Laws E, Paranjpye RN, Strom MS, Chen A, Hasan NA, Huq A, Noriea NF 3rd, Grimes DJ, Colwell RR, 2012. Ecology of Vibrio parahaemolyticus and Vibrio vulnificus in the coastal and estuarine waters of Louisiana, Maryland, Mississippi, and Washington, United States. Appl Environ Microb 78:7249-57.

Le Roux F, Wegner K, Baker-Austin C, Vezzulli L, Osorio CR, Amaro C, Ritchie JM, Defoirdt T, Destoumieux-Garzón D, Blokesch M, Mazel D, Jacq A, Cava F, Gram L, Wendling CC, Strauch E, Kirschner A, Huehn S, 2015. The emergence of Vibrio pathogens in Europe: ecology, evolution and pathogenesis. Front Microbiol 6:830.

Lopez-Joven C, deBlas I, Furones MD, Roque A, 2015. Prevalences of pathogenic and nonpathogenic Vibrio parahaemolyticus in mollusks from the Spanish Mediterranean Coast. Front Microbiol 6:736.

Lopez-Joven C, Roque A, Furones MD, Deblas I, 2014. Spatial and temporal distribution of Vibrio vulnificus in bivalve molluscs from the Spanish Mediterranean coast. Adelaide, South Australia. World Aquaculture Society. Available from: https://www.was.org/documents/MeetingPr esentations/WA2014/WA2014_0383.pdf

Mahmud ZH, Neogi SB, Kassu A, Mai Huong BT, Jahid IK, Islam MS, Ota F, 2008. 
Occurrence, seasonality and genetic diversity of Vibrio vulnificus in coastal seaweeds and water along the Kii Channel, Japan. FEMS Microbiol Ecol 64:209-18.

Oberbeckmann S, Fuchs BM, Meiners M, Wichels A, Wiltshire KH, Gerdts G, 2012. Seasonal dynamics and modeling of a Vibrio community in coastal waters of the Northern Sea. Microb Ecol 63:543-51.

Ottaviani D, Leoni F, Serra R, Serracca L, Decastelli L, Rocchegiani E, Masini L, Canonico C, Talevi G, Carraturo A, 2012. Nontoxigenic Vibrio parahaemolyticus strains causing acute gastroenteritis. J Clin Microbiol 50:4141-3.

Parvathi A, Kumar HS, Karunasagar I, Karunasagar I, 2004. Detection and enumeration of Vibrio vulnificus in oysters from two estuaries along the southwest coast of India, using molecular methods. Appl Environ Microb 70:6909-13.

Parveen S, Hettiarachchi KA, Bowers JC, Jones JL, Tamplin ML, McKay R, Beatty W, Brohawn K, Dasilva LV, Depaola A, 2008. Seasonal distribution of total and patho- genic Vibrio parahaemolyticus in Chesapeake Bay oysters and waters. Int J Food Microbiol 128:354-61.

Passalacqua PL, Zavatta E, Bignami G, Serraino A, Serratore P, 2016. Occurrence of Vibrio parahaemolyticus, Vibrio cholerae and Vibrio vulnificus in the clam Ruditapes philippinarum (Adams \& Reeve, 1850) from Emilia-Romagna and Sardinia, Italy. Ital J Food Safety 5:41-6.

Pfeffer CS, Hite MF, Oliver JD, 2003. Ecology of Vibrio vulnificus in estuarine waters of Eastern Northern Carolina. Appl Environ Microb 69:3526-31.

Ramirez GD, Buck GW, Smith AK, Gordon KV, Mott JB, 2009. Incidence of Vibrio vulnificus in estuarine waters of the south Texas Coastal Bend Region. J Appl Microbiol 107:2047-53.

Raghunath P, 2015. Roles of thermostable direct hemolysin (TDH) and TDH-related hemolysin (TRH) in Vibrio parahaemolyticus. Front Microbiol 5:805.

Reid C, Gorick G, Edwards M, 2011. Climate change and European marine ecosystem research. Sir Alister Hardy Foundation for Ocean Science, Plymouth, UK.

Serratore P, Ciulli S, Piano A, Cariani A, 2014. Criticism of the purification process of bivalve shellfish. Literature review and our industrial research experiences. In: Hay RM, ed. Shellfish, human consumption health implication and conservation concerns. Nova Publishers, NY, USA. pp. 1-50.

Siboni N, Balaraju V, Carney R, Labbate M, Seymour JR, 2016. Spatiotemporal dynamics of Vibrio spp. within the Sydney Harbour Estuary. Front Microbiol 7:460.

Takemura AF, Chien DM, Polz MF, 2014. Associations and dynamics of Vibrionaceae in the environment, from the genus to the population level. Front Microbiol 5:38.

Urquhart EA, Jones SH, Yu JW, Schuster BM, Marcinkiewicz AL, Whistler CA, Cooper VS, 2016. Environmental conditions associated with elevated Vibrio parahaemolyticus concentrations in Great Bay Estuary, New Hampshire. PLoS One 11:e0155018. 